11. Шрейдер Ю.А. Тезаурусы в информатике и логической семантике // Научно-техническая информация. Сер. 2. Информационные процессы и системы. 1971. № 3. С. 21-24.

12. Харари Ф. Теория графов. М.: УРСС, 2003. $300 \mathrm{c}$.

13. Григорьев С.Г., Гриншкун В.В. Информатизация образования. Фундаментальные основы: учебник для студентов педагогических вузов и слушателей системы повышения квалификации педагогов. М.: МГПУ, 2005. $231 \mathrm{c}$.
14. Григорьев С.Г., Гриншкун В.В., Демкин В.П., Краснова Г.А., Макаров С.И., Роберт И.В. Концепция образовательных электронных изданий и ресурсов - шаг на пути к качественному образованию // Информационные технологии в образовании: сб. тр. междунар. конф.-выставки «ИТО-2002». Ч. 6: Пленарные доклады. М.: МИФИ, 2002. С. 11-14.

15. Григорьев С.Г., Гриншкун В.В., Демкин В.П., Краснова Г.А., Макаров С.И., Роберт И.В. Разработка концепции образовательных электронных изданий и ресурсов // Открытое и дистанционное образование. 2002. № 3 (7). С. 31-33.

\title{
TECHNOLOGY OF CREATION OF ELECTRONIC EDUCATIONAL RESOURCES FOR TRAINING SPECIALISTS IN DIGITAL ECONOMY
}

(C) 2019

Makarov Sergey Ivanovich, doctor of pedagogical sciences, professor,

head of Higher Mathematics and Economic-Mathematical Methods Department

Sevastyanova Svetlana Aleksandrovna, candidate of pedagogical sciences, associate professor of Higher Mathematics and Economic-Mathematical Methods Department

Kurganova Mariya Vladimirovna, candidate of economical sciences, associate professor of Higher Mathematics and Economic-Mathematical Methods Department Samara State University of Economics (Samara, Russian Federation)

Abstract. The professional training of specialists in the field of the digital economy is a promising direction in the development of economic education. The transition to digital technologies in management, banking, manufacturing, commerce, communications determines the emergence of new requirements for the professional and general competencies of university graduates. It is necessary to create an innovative vocational training system based on the use of electronic teaching aids and digital technologies. The implementation of this task should begin with the development of scientifically determined approaches to the creation of teaching aids that take into account all kinds of efficiency factors. This determines the importance of the task of scientific and methodological substantiation of the technology for creating electronic educational resources for the training of specialists in a new format. The paper proposes an analytical approach to determining the content and structure of the basic component of the methodological system an electronic textbook. The expediency of its use in order to develop necessary competencies of the individual and group levels is substantiated. It is proposed to use a matrix form of information representation and elements of matrix and vector analysis to structure the material. A mathematical model has been developed that describes structural relationships between the concepts of the thesaurus. The structural elements in this model are the glossary concepts of an academic discipline. The possibilities of using the model for unification and automation of information processing during the selection of textbook content in various educational fields are discussed. Examples of using the proposed model in various subject areas are given. The authors describe how to represent a model based on graph theory and methods for solving the problem of the presence of cycles in this semantic structure. The main conclusions and results of the study can be used for the practical development of electronic learning tools, automating the process of structuring their content and methods of use in the educational process.

Keywords: higher education; educational technologies; training for digital economy; electronic textbook; electronic educational resources; thesaurus of subject area; creation of electronic teaching aids; digitalization of education; mathematical modeling in pedagogy; technology of electronic teaching aids creation.

$* * *$

\section{СОВРЕМЕННЫЙ ВЗГЛЯД НА ФОРМИРОВАНИЕ СЕРВИСНО-ЭКСПЛУАТАЦИОННОЙ КОМПЕТЕНТНОСТИ СПЕЦИАЛИСТА ПО БЕЗОПАСНОЙ ЭКСПЛУАТАЦИИ ОПАСНЫХ ПРОИЗВОДСТВЕННЫХ ОБЪЕКТОВ}

(C) 2019

Панишев Андрей Львович, начальник Тольяттинского межтерриториального отдела

по надзору за промышленной и энергетической безопасностью

Средне-Поволжское управление Федеральной службы по экологическому,

технологическому и атомному надзору (г. Тольятти, Самарская область, Российская Федерация)

Горина Лариса Николаевна, доктор педагогических наук,

профессор кафедры управления промышленной и экологической безопасности

Тольяттинский государственный университет (2. Тольятти, Самарская область, Российская Федерация)

Аннотаиия. В статье приводятся результаты исследования, направленные на повышение качества подготовки в высших учебных заведениях специалистов, которые в дальнейшем будут использованы на промыш- 
ленных предприятиях, где эксплуатируются опасные производственные объекты. От качества подготовки специалистов зависит уровень промышленной безопасности опасных производственных объектов и, как следствие, вероятность возникновения аварийных ситуаций. В настоящий момент, несмотря на общую тенденцию снижения аварий на опасных производственных объектах за последние десять лет, их количество остается довольно значительным. При этом социально-экономический ущерб от аварий может оцениваться в 600-700 млрд рублей в год, что негативно скажется на экономической стабильности Российской Федерации. Обязанности организации, эксплуатирующей ОПО и ее работников, определены законодательством. Содержание образования должно учитывать эти базовые требования, которые должны быть сформированы в отдельные темы. Соответственно, при проектировании содержания обучения используется модульный принцип. Формирование содержания в виде модулей позволит обеспечить организационное и содержательное единство подготовки обучающихся. В качестве основных методов учебного процесса принимаем лекции и практические занятия, а форм - групповые и индивидуальные. Усвоение материала по результатам лекций, практических занятий и самоподготовки должно позволить обучающимся сформировать качества, указанные в нашей профессиограмме. Степень усвоения предложенного для изучения учебного материала должна быть проверена в ходе мероприятий по контролю, начиная от начального - входного контроля (ВК) и заканчивая заключительным - итоговым контролем.

Ключевые слова: технология; профессиограмма; модуль; образовательная программа; образовательный подход; содержание обучения; контроль; оценивание; мониторинг; сервисно-эксплуатационная компетентность; специалист; промышленная безопасность; опасный производственный объект; авария.

Анализ причин аварийности и смертельного травматизма на опасных производственных объектах свидетельствуют о том, что главными из них по-прежнему остаются так называемый «человеческий фактор», недостаточная квалификация специалистов и руководителей предприятий, а иногда и умышленное игнорирование требований федеральных норм и правил, несоблюдение производственной дисциплины» [1].

С учетом того, что виды деятельности в области промышленной безопасности довольно разнообразны, среди них - строительство, эксплуатация, расширение, реконструкция, капитальный ремонт, техническое перевооружение, консервация и ликвидация опасного производственного объекта, то это требует и наличия специалистов соответствующей компетентности, по каждому направлению деятельности [2]. Исполнение указанного невозможно без соответствующего систематического обучения персонала. В данном случае мы понимаем, что процесс обучения человека протекает всю его сознательную жизнь. Профессиональное образование как процесс - одно из звеньев единой системы непрерывного образования, а как результат - подготовленность человека к определенному виду трудовой деятельности, профессии, подтвержденная результирующим документом (аттестатом, дипломом, свидетельством) об окончании соответствующего учебного заведения [3].

Существующая система образования предполагает четыре ступени образования: дошкольного, школьного, профессионального и дополнительного.

Проанализировав каждую из ступеней образования на предмет наличия в образовательных стандартах компетенций по вопросам обеспечения промышленной безопасности, мы пришли к выводу о том, что все они не содержат конкретных компетенций по направлениям обеспечения промышленной безопасности и отражают, в лучшем случае, вопросы охраны труда, экологии и действий в случае чрезвычайных ситуаций.

Возможность повлиять на ситуацию появилась путем применения с 1 января 2019 г. Федеральных государственных образовательных стандартов высшего образования (ФГОС $3++)$, которые позволяют образовательным организациям формировать программы обучения с учетом запросов предприятий на требуемых специалистов и, соответственно, самостоятельно формировать профессиональные компетен- ции учащихся, исходя из требований промышленной безопасности при необходимости.

Но, несмотря на вновь открывающиеся возможности, мы констатируем, что ни одна из существующих ступеней образования не отвечает требованиям современного состояния и развития системы промышленной безопасности и антитеррористической защищенности опасных производственных объектов, поскольку не имеет ни единой типовой программы подготовки специалиста по данному направлению, ни технологии, гарантирующей запрашиваемый российским обществом результат. Отмечаем также отсутствие преемственности подготовки по образовательным программам при переходе с одной ступени на другую, взаимосвязь содержания дисциплин естественного цикла, а также теоретической и прикладной составляющей процесса подготовки.

Казалось бы, изменить ситуацию могла бы система дополнительного образования, но, к сожалению, этого не происходит: фактически при проверке знаний в комиссиях Ростехнадзора до 20\% экзаменуемых не проходит проверку знаний с первого раза, в том числе по причине некачественной подготовки и обучения [4].

Соответственно, в данной работе мы предлагаем конкретные мероприятия по повышению качества подготовки специалистов.

В целях изменения ситуации, связанной с подготовкой специалистов в области промышленной безопасности, нами были проведены исследования состояния системы их профессиональной подготовки.

Для начала был проведен анализ содержания различных образовательных подходов [5-16], по результатам которого установлено, что теоретико-методологическими подходами, элементы которых могут быть использованы для формирования видов профессиональной деятельности специалиста в области промышленной безопасности, являются: системный подход, аксиологический подход, андрагогический подход, практико-ориентированный подход. На базе указанных подходов, по нашему мнению, могут быть сформированы образовательные программы по направлениям профессиональной деятельности специалиста, осуществляющего эксплуатацию опасного производственного объекта. Указанные программы должны учитывать совокупность требуемых свойств и качеств специалиста, которые могут быть описаны 
с использованием профессиографического подхода. В нашем случае профессиограмма будет выступать как модель необходимого уровня профессиональных и личностных качеств специалиста [17-19].

Для построения профессиограммы специалиста в области промышленной безопасности нами были исследованы требования: единого квалификационного справочника должностей руководителей, специалистов и служащих; профессиональных стандартов для областей профессиональной деятельности; федеральных государственных образовательных стандартов высшего образования по направлениям подготовки бакалавриата, по основным направлениям деятельности в промышленном производстве, где эксплуатируются ОПО [20; 21-29; 30-37]. В качестве подхода при анализе производственных функций нами был использован метод сравнения требований к определенным должностям руководителей и специалистов, указанным в квалификационном справочнике, профессиональных стандартах и образовательных стандартах.

По итогам рассмотрения результатов анализа, положений единого квалификационного справочника должностей руководителей, специалистов и служащих, профессиональных стандартов, федеральных государственных образовательных стандартов высшего образования по направлениям подготовки бакалавриата и фактических требований к эксплуатации опасного производственного объекта, была сформирована профессиограмма специалиста в области промышленной безопасности (рис. 1).

Профессиограмма, которая разработана нами, является базовой для специалиста в области промышленной безопасности, в зависимости от класса опасности опасного производственного объекта в нее могут быть внесены соответствующие изменения и дополнения. На основании построенной профессиограммы нами была сформирована система подготовки специалиста в области промышленной безопасности [38].

Считаем, что процесс образования в области безопасности жизнедеятельности может быть представлен в виде единой системы, описываем эту систему посредством модели, состоящей из структурных составляющих этой системы [39; 40].

Нами предлагается четырехуровневая модель системы подготовки специалиста в области промышленной безопасности, основанная на анализе состояния промышленной безопасности, уровня подготовки персонала, эксплуатирующего опасные производственные объекты и содержания ФГОС. В качестве основных элементов системы подготовки специалиста в области промышленной безопасности мы используем следующие подсистемы: ступень образования бакалавра, ступень образования магистра, профессиональную деятельность и дополнительное профессиональное образование. В данном случае под целью дополнительного профессионального образования мы понимаем совершенствование имеющихся у специалиста профессиональных, знаний, умений и навыков.

Нами были проанализированы ФГОС [31; 41-43] подготовки специалистов для наиболее распространенных в отраслях промышленности опасных производственных объектов, на которых эксплуатируются: подъемные сооружения и оборудование, работающее под избыточным давлением. В соответствии с ФГОС, в результате освоения программы бакалавриата и магистратуры у выпускника должны быть сформированы общекультурные, общепрофессиональные и про- фессиональные компетенции. То есть под конечным результатом образовательного процесса рассматриваем «компетенцию».

С учетом мнения авторов [9; $10 ; 44 ; 45]$, понимаем, что на стадии получения высшего образования можно говорить лишь о наличии тех или иных компетенций, оценивать компетентность выпускника можно будет только тогда, когда он приступит к самостоятельной профессиональной деятельности. На производстве подтверждением знаний требований промышленной безопасности и готовности специалиста к выполнению поставленных задач является прохождение им аттестации (проверки знаний). В соответствии с требованиями законодательства [2] работники, осуществляющие свою деятельность в области промышленной безопасности, обязаны не реже одного раза в пять лет проходить аттестацию в области промышленной безопасности.

На каждой ступени образования и в процессе профессиональной деятельности происходит постепенное формирование определенного набора качеств специалиста в области промышленной безопасности. С учетом мнения авторов [40; 46], условно мы подразделяем эти этапы на пороговое формирование; базовое формирование; профессиональное. Профессиональный уровень представляет собой набор качеств, необходимый для осуществления конкретного профессионального вида деятельности. Это специальные по отношению к базовому уровню качества, которые способствуют реализации целей его деятельности.

Помимо сугубо профессиональных качеств, специалисту потребуется и ряд компонентов, необходимых для осуществления профессиональной деятельности, в частности: качества личности; качества мышления; коммуникативные качества.

Далее следуя общей теории систем, с учетом [39; 40; 47], нами сформирована модель системы формирования сервисно-эксплуатационной компетентности специалиста по безопасной эксплуатации опасных производственных объектов (рис. 2). Представленная система является иерархической. Построенная нами модель системы формирования компетентности специалиста по безопасной эксплуатации опасных производственных объектов позволяет перейти к рассмотрению вариантов технологии формирования сервисно-эксплуатационной компетентности специалиста по безопасной эксплуатации опасных производственных объектов.

Обязанности организации, эксплуатирующей ОПО и ее работников, определены законодательством [2]. Содержание курса должно учитывать эти базовые требования, которые должны быть сформированы в отдельные темы. Соответственно, используем при проектировании содержания обучения модульный принцип. Считаем, что формирование содержания в виде модулей позволит обеспечить организационное и содержательное единство подготовки обучающихся. В целом, под модулем будем понимать - целевой функциональный узел [48], состоящий из теоретической и практической частей. В качестве основных методов учебного процесса принимаем лекции и практические занятия, а в качестве форм - групповые и индивидуальные. Усвоение материала по результатам лекций, практических занятий и самоподготовки должно позволить обучающимся сформировать качества, указанные в нашей профессиограмме. Степень усвоения предложенного для изучения 
Панишев А.Л., Горина Л.Н.

учебного материала должна быть проверена в ходе мероприятий по контролю, начиная от начального входного контроля (ВК) и заканчивая заключительным - итоговым контролем.

В целом соглашаясь с авторами [5; 40; 49-54], что процесс формирования педагогических систем, технологий или процессов - многоступенчатая деятельность, которая предусматривает ряд последовательных операций, считаем, что предлагаемая нами технология обучения специалиста в области промышленной безопасности (рис. 2) позволит решить задачу качественной подготовки требуемого специалиста.

В целях проверки предложенной модели технологии образования были проанализированы отдельные программы подготовки студентов кафедры «Управление промышленной и экологической безопасностью» ФГБОУ ВО «Тольяттинский государственный университет». По итогам анализа можно заключить следующее: содержание теоретического курса в основном полностью отражает содержание нормативных правовых документов в области промышленной безопасности. При этом считаем необходимым расширить направления по теме «организация и осуществление производственного контроля», с учетом отраслевой принадлежности ОПО. Содержание практического курса недостаточно полно охватывает весь спектр регламентированных документов в области промышленной безопасности, а представляемые для оформления документы требуют актуализации и соответствующего регламента заполнения.

Далее с учетом перемен, происходящих в системе образования, соглашаясь с авторами [55], считаем, что всегда будет оставаться актуальным вопрос изучения состояния образовательного процесса, а в процессе подготовки важное место будет занимать система оценки деятельности обучающегося.

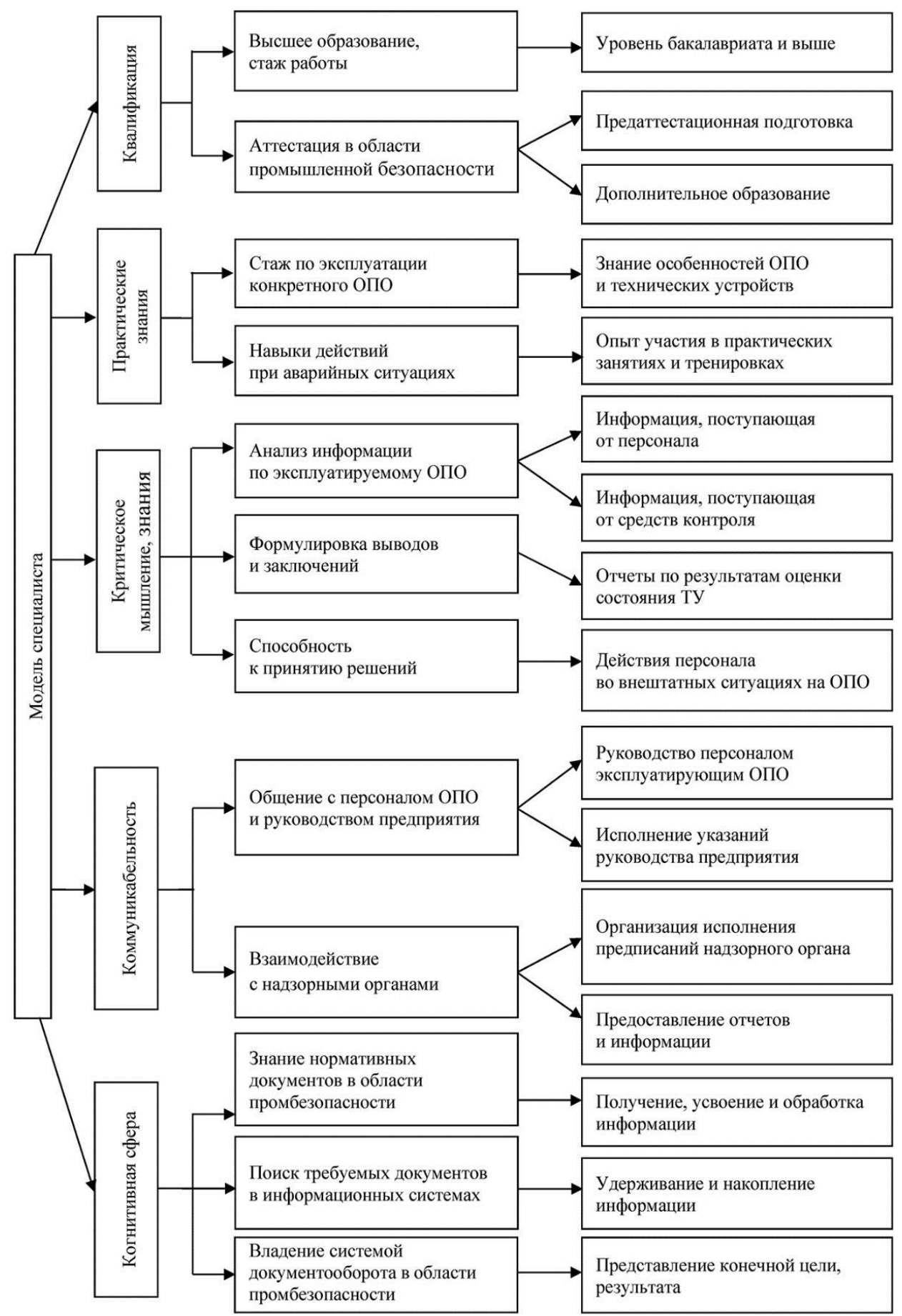

Рисунок 1 - Профессиограмма специалиста в области промышленной безопасности 


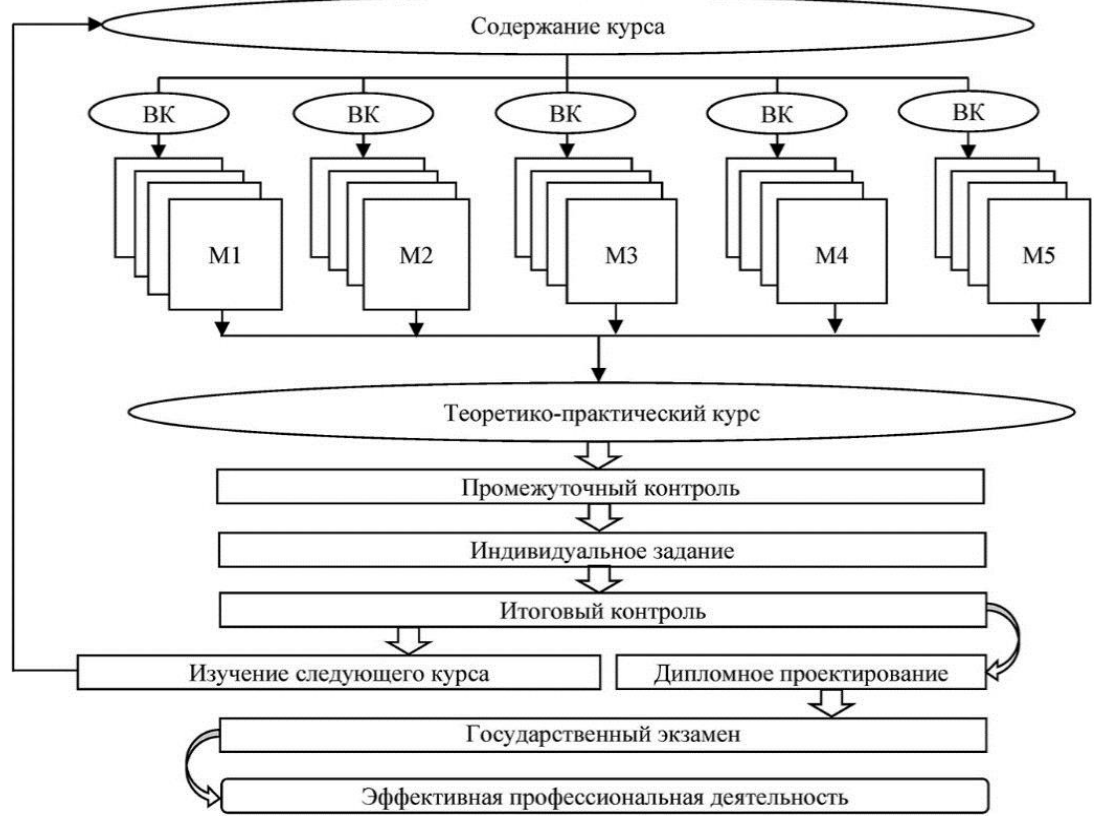

Рисунок 2 - Технология подготовки специалиста в области промышленной безопасности

Для мониторинга состояния, динамики учебновоспитательного процесса и в целях оценки сформированности сервисно-эксплуатационной компетентности специалиста по безопасной эксплуатации опасных производственных объектов, на базе профессиограммы нами были выработаны соответствующие критерии, а также подобраны методы и средства осуществления мониторинга и контроля сформированности структурных элементов сервисно-эксплуатационной компетентности. В ходе проведения входного, рубежного и итогового контроля предлагается использовать методы по направлению качества: знаний, навыков и владений - тестирование, коллоквиум и эссе. Указанные методы должны применяться в зависимости от необходимости контроля усвоения качества конкретного содержания.

В любой сфере человеческой деятельности важным является достижение поставленных целей. Одним из компонентов при рассмотрении эффективности выполнения задач на пути достижения цели является процесс оценивания, результатом которого служит оценка [56]. Наиболее востребована в любом направлении деятельности объективная оценка результатов.

На наш взгляд при оценивании сформированности компетентности специалиста в области промышленной безопасности должны применяться следующие методы: собеседование, разнообразные тестовые задания и анкетирование. Далее, соглашаясь с авторами [57; 58], стоит отметить важность готовности обучающегося к решению практических задач, положительный результат которых во многом зависит от его способности правильно мотивировать себя, это в итоге сказывается и на оперативности решения поставленной задачи. Быстрое принятие правильного решения во внештатной ситуации - важное качество для будущего специалиста в области промышленной безопасности.

В нашем случае, при подготовке обучающегося под оцениванием будем понимать некий процесс соизмерения имеющегося набора сформированных компетенций с теми, которые должны быть в идеале у специалиста в области промышленной безопасности. В качестве эталонных характеристик взяты качества из профессиограммы специалиста по безопасной эксплуатации опасных производственных объектов. По результатам анализа имеющихся оценочных средств нами предлагаются к применению, как наиболее эффективные, тесты различной формы, коллоквиумы и эссе.

Для правильного понимания уровня достижения обучающимся ожидаемого результата считаем правильным применение оценочной балльной шкалы. Исходя из количественного показателя баллов обучающегося, полученного в ходе оценочных процедур, мы будем определять уровни достижения им результатов в обучении [59]. В этой связи отмечаем, что положительным результатом процесса обучения будет считаться уровень - выше базового. В целях своевременной реакции на возможные ситуации, приводящие к снижению уровня - ниже базового, предлагается разработанная нами система анкетирования обучающихся, которая позволяет сформировать обратную связь процесса обучения [60]. Наличие такой обратной связи позволяет преподавателю незамедлительно отреагировать на возникающие проблемы, связанные с освоением обучающимся учебного материала. Указанные методы должны применяться в зависимости от необходимости контроля усвоения качества конкретного содержания.

Оценить степень освоения учащимся учебного материала и, соответственно, готовность к выполнению предстоящей профессиональной деятельности предстоит в ходе экзамена [61]. Для его проведения нами сформированы экзаменационные вопросы на основе требований законодательства в области промышленной безопасности и максимально сориентированные на практическую деятельность по эксплуатации ОПО.

Достижение целей образования невозможно без правильной настройки всех элементов системы. В нашем случае, мы провели исследования по всем этапам обучающего процесса, в целях его целостного формирования на основе разработанной нами профессиограммы специалиста по безопасной эксплуатации опасных производственных объектов.

Проконтролировать качество результатов образовательного процесса на каждом этапе, а при необходимости внести соответствующие корректировки в деятельность обучаемого и преподавателя позволяет предложенная нами система оценивания. Она дает возможность соизмерения имеющегося набора сфор- 
мированных компетенций с теми, которые должны быть в идеале у специалиста в области промышленной безопасности. В качестве эталонных характеристик взяты качества из профессиограммы специалиста по безопасной эксплуатации опасных производственных объектов.

Наличие единой системы оценивания сформированности компетентности специалиста по безопасной эксплуатации опасных производственных объектов, на наш взгляд, давало бы возможность формирования универсальных программ эффективной подготовки специалистов в области промышленной безопасности как на стадии получения высшего образования, так и при получении дополнительного образования.

\section{Список литературы:}

1. О состоянии промышленной безопасности в Приволжском федеральном округе: практика, проблемы и пути их решения. Задачи на 2018 год [Электронный ресурс] // Федеральная служба по экологическому, технологическому и атомному надзору. http://gosnadzor.ru/news/64/2145.

2. О промышленной безопасности опасных производственных объектов: Федеральный закон от 21.07.1997 № 116-Ф3 [Электронный ресурс] // Кодификация РФ. - https://rulaws.ru/laws/federalnyy-zakonot-21.07.1997-n-116-fz.

3. Об образовании в Российской Федерации: Федеральный закон от 29.12.2012 № 273-Ф3 [Электронный ресурс] // Кодификация РФ. - https://rulaws.ru/ laws/federalnyy-zakon-ot-29.12.2012-n-273-fz.

4. Данилина Н.Е., Панишев А.Л. Компетентность и осведомленность персонала в области промышленной безопасности // Международный научный журнал «Символ науки». 2016. № 7-2. С. 48-53.

5. Андреев В.И. Педагогика: учеб. курс для творческого саморазвития. 3-е изд. Казань: Центр инновационных технологи, 2003. 608 с.

6. Бусыгин А.Г., Бусыгина А.Л. Методологические основания обучения студентов здоровьесбережению // Самарский научный вестник. 2013. № 4 (5). С. 40-43.

7. Гринкруг Л., Фишман Б. Аксиологически ориентированное образование: основополагающие принципы // Высшее образование в России. 2006. № 1. C. 27-33.

8. Загвязинский В.И. Наступит ли эпоха возрождения?.. Стратегия инновационного развития российского образования: монография. 2-е изд., перераб. и доп. М.: Логос, 2015. 140 с.

9. Зеер Э.Ф. Идентификация универсальных компетенций выпускников работодателем // Высшее образование в России. 2007. № 11. С. 39-46.

10. Зимняя И.А. Ключевые компетентности как результативно-целевая основа компетентностного подхода в образовании. Авторская версия // Материалы методологического семинара. М.: Исследовательский центр проблем качества подготовки специалистов, 2004. 42 с.

11. Змеев С.И. Образование взрослых и андрагогика в реализации концепции непрерывного образования в России // Отечественная и зарубежная педагогика. 2015. № 3 (24). С. 94-101.

12. Змеев С.И. Андрагогика: основы теории и технологии обучения взрослых. М.: OOO «PER SE», 2007. $272 \mathrm{c}$.

13. Змеев С.И. Применение андрагогических принципов обучения в подготовке и повышении квалификации специалистов // Человек и образование. М.:
Академический вестник Института педагогического образования и образования взрослых РАО. 2014. № 1. C. $8-14$.

14. Змеев С.И. Технология обучения взрослых: учеб. пособие для студ. высш. учеб. заведений. М.: Издательский центр «Академия», 2002. 128 с.

15. Климов Е.А. Психология профессионального самоопределения: учеб. пособие для студ. высш. пед. учеб. заведений. М.: Издательский центр «Академия», 2004. 304 с.

16. Сластенин В.А., Исаев И.Ф., Шиянов Е.Н. Педагогика: учеб. пособие для студ. высш. пед. учеб. заведений / под ред. В.А. Сластенина. М.: Издательский центр «Академия», 2002. 576 с.

17. Андреев А.А. Педагогика высшей школы. Новый курс М.: Московский международный институт эконометрики, информатики, финансов и права, 2002. $264 \mathrm{c}$.

18. Горина Л.Н., Данилина Н.Е. Моделирование системы экологической и пожарной безопасности человека в образовательном процессе // Известия Самарского научного центра РАН. 2012. Т. 14, № 2 (4). C. $884-887$.

19. Горина Л.Н., Данилина Н.Е., Фрезе Т.Ю., Назаров А.Г. Методология проектирования системы подготовки специалистов по пожарной безопасности // Вектор науки Тольяттинского государственного университета. 2010. № 2 (12). С. 185-187.

20. О реестре профессиональных стандартов (перечня видов профессиональной деятельности): приказ Минтруда РФ от 29.09.2014 № 667н [Электронный ресурс] // Кодификация РФ. - https://rulaws.ru/ acts/prikaz-mintruda-rossii-ot-29.09.2014-n-667n.

21. Порядок применения Единого квалификационного справочника должностей руководителей, специалистов и служащих: постановление Минтруда РФ от 09.02.2004 № 9 [Электронный ресурс] // Кодификация РФ. - https://rulaws.ru/acts/postanovleniemintruda-rf-ot-09.02.2004-n-9.

22. Профессиональный стандарт «Специалист по эксплуатации наружных газопроводов низкого давления»: приказ Минтруда РФ от 11.04.2014 № 224н [Электронный ресурс] // Кодификация РФ. - https:// rulaws.ru/acts/prikaz-mintruda-rossii-ot-11.04.2014-n-224n.

23. Профессиональный стандарт «Специалист по эксплуатации котлов на газообразном, жидком топливе и электронагреве»: приказ Минтруда РФ от 11.04.2014 № 237н [Электронный ресурс] // Кодификация РФ. - https://rulaws.ru/acts/prikaz-mintrudarossii-ot-11.04.2014-n-237n.

24. Профессиональный стандарт «Работник по организации эксплуатации электротехнического оборудования тепловой электростанции»: приказ Минтруда РФ от 06.07.2015 № 428н [Электронный ресурс] // Кодификация РФ. - https://rulaws.ru/acts/ prikaz-mintruda-rossii-ot-06.07.2015-n-428n.

25. Профессиональный стандарт «Работник по оперативному управлению объектами тепловой электростанции»: приказ Минтруда РФ от 15.12.2014 № 1038н [Электронный ресурс] // Кодификация РФ. - https://rulaws.ru/acts/prikaz-mintruda-rossii-ot-15.12.2014n-1038n.

26. Профессиональный стандарт «Специалист по техническому обслуживанию и ремонтам в металлургическом производстве»: приказ Минтруда РФ от 23.01.2017 № 67н [Электронный ресурс] // Кодификация РФ. - https://rulaws.ru/acts/prikaz-mintruda-rossiiot-23.01.2017-n-67n. 
27. Профессиональный стандарт «Специалист литейного производства в автомобилестроении»: приказ Минтруда РФ от 30.10.2018 № 678н [Электронный ресурс] // Кодификация РФ. - https://rulaws.ru/ acts/prikaz-mintruda-rossii-ot-30.10.2018-n-678n.

28. Профессиональный стандарт «Специалист сварочного производства»: приказ Минтруда РФ от 03.12.2015 № 975н [Электронный ресурс] // Кодификация РФ. - https://rulaws.ru/acts/prikaz-mintruda-rossiiot-03.12.2015-n-975n.

29. Профессиональный стандарт «Специалист по оценке соответствия подъемных сооружений требованиям промышленной безопасности»: приказ Минтруда РФ от 31.05.2018 № 343н [Электронный ресурс] // Кодификация РФ. - https://rulaws.ru/acts/ prikaz-mintruda-rossii-ot-31.05.2018-n-343n.

30. Федеральный государственный образовательный стандарт высшего образования по направлению подготовки 08.03.01 Строительство (уровень бакалавриата): приказ Минобрнауки РФ от 12.03.2015 № 201 [Электронный ресурс] // Кодификация РФ. https://rulaws.ru/acts/prikaz-minobrnauki-rossii-ot-12.03.2015n-201.

31. Федеральный государственный образовательный стандарт высшего образования по направлению подготовки 13.03.01 Теплоэнергетика и теплотехника (уровень бакалавриата): приказ Минобрнауки РФ от 01.10.2015 № 1081 [Электронный ресурс] // Кодификация РФ. - https://rulaws.ru/acts/prikaz-minobrnaukirossii-ot-01.10.2015-n-1081.

32. Федеральный государственный образовательный стандарт высшего образования по направлению подготовки 13.03.02 Электроэнергетика и электротехника (уровень бакалавриата): приказ Минобрнауки РФ от 03.09.2015 № 955 [Электронный ресурс] // Кодификация РФ. - https://rulaws.ru/acts/prikazminobrnauki-rossii-ot-03.09.2015-n-955.

33. Федеральный государственный образовательный стандарт высшего образования по направлению подготовки 15.03.01 Машиностроение (уровень бакалавриата): приказ Минобрнауки РФ от 03.09.2015 № 957 [Электронный ресурс] // Кодификация РФ. https://rulaws.ru/acts/prikaz-minobrnauki-rossii-ot-03.09.2015n-957.

34. Федеральный государственный образовательный стандарт высшего образования по направлению подготовки 15.03.02 Технологические машины и оборудование (уровень бакалавриата): приказ Минобрнауки РФ от 20.10.2015 № 1170 [Электронный ресурс] // Кодификация РФ. - https://rulaws.ru/acts/ prikaz-minobrnauki-rossii-ot-20.10.2015-n-1170.

35. Федеральный государственный образовательный стандарт высшего образования по направлению подготовки 22.03.02 Металлургия (уровень бакалавриата): приказ Минобрнауки РФ от 04.12.2015 № 1427 [Электронный ресурс] // Кодификация РФ. https://rulaws.ru/acts/prikaz-minobrnauki-rossii-ot-04.12.2015n-1427.

36. Федеральный государственный образовательный стандарт высшего образования по направлению подготовки 23.03.03 Эксплуатация транспортно-технологических машин и комплексов (уровень бакалавриата): приказ Минобрнауки РФ от 14.12.2015 № 1470 [Электронный ресурс] // Кодификация РФ. https://rulaws.ru/acts/prikaz-minobrnauki-rossii-ot-14.12.2015 $-n-1470$

37. Федеральный государственный образовательный стандарт высшего образования по направлению подготовки 13.03.03 Энергетическое машиностроение (уровень бакалавриата): приказ Минобрнауки РФ от 01.10.2015 № 1083 [Электронный ресурс] // Кодификация РФ. - https://rulaws.ru/acts/prikazminobrnauki-rossii-ot-01.10.2015-n-1083.

38. Иванова А.В. Профессиограмма как эталонная модель специалиста // Актуальные вопросы современной педагогики: мат-лы III междунар. науч. конф. (г. Уфа, март 2013 г.). Уфа: Лето, 2013. С. 154-155.

39. Беспалько В.П. Слагаемые педагогической технологии. М.: Педагогика, 1989. 192 с.

40. Горина Л.Н. Культура безопасности жизнедеятельности: методологический и технологический аспекты: монография / под науч. ред. Ю.К. Черновой. Тольятти: Изд-во ТГУ, 2001. 264 с.

41. Федеральный государственный образовательный стандарт высшего образования по направлению подготовки 23.03.02 Наземные транспортно-технологические комплексы (уровень бакалавриата): приказ Минобрнауки РФ от 06.03.2015 № 162 [Электронный pecypc] // Кодификация РФ. - https://rulaws.ru/acts/ prikaz-minobrnauki-rossii-ot-06.03.2015-n-162.

42. Федеральный государственный образовательный стандарт высшего образования по направлению подготовки 13.04.01 Теплоэнергетика и теплотехника (уровень магистратуры): приказ Минобрнауки РФ от 21.11.2014 № 1499 [Электронный ресурс] // Кодификация РФ. - https://rulaws.ru/acts/prikaz-minobrnaukirossii-ot-21.11.2014-n-1499.

43. Федеральный государственный образовательный стандарт высшего образования по направлению подготовки 08.04.01 Строительство (уровень магистратуры): приказ Минобрнауки РФ от 30.10.2014 № 1419 [Электронный ресурс] // Кодификация РФ. https://rulaws.ru/acts/prikaz-minobrnauki-rossii-ot-30.10.2014n-1419.

44. Татур Ю.Г. Высшее образование: методология и опыт проектирования: учеб. пособие. М.: Университетская книга; Логос, 2006. 256 с.

45. Хуторской А.В. Ключевые компетенции и образовательные стандарты: доклад на отделении философии образования и теории педагогики РАО 23 апреля 2002. М.: Центр «Эйдос», 2002.

46. Львов Л.В. Технология формирования учебнопрофессиональной компетентности (КОЕЦЕПТ). Челябинск: ЧГАУ, ЮУНОЦРАО, 2007. 151 с.

47. The Global Human Capital Report 2017 [El. resource] // World Economic Forum. - https://weforum. org/reports/the-global-human-capital-report-2017.

48. О реестре профессиональных стандартов (перечня видов профессиональной деятельности): приказ Минтруда РФ от 29.09.2014 № 667н [Электронный ресурс] // Кодификация рф. - https://rulaws.ru/ acts/prikaz-mintruda-rossii-ot-29.09.2014-n-667n.

49. Norstrom A., Hovinen T. Working Day Model for Students in Chemical and Materials Engineering // Proc. 12th Int. CDIO Conf., Turku University of Applied Sciences. Turku, Finland, June 12-16, 2016. P. 489-496.

50. Isaksson-Persson H., Gumaelius L. CDIO Implementation in Swedish Upper Secondary Education // Proc. 12th Int. CDIO Conf., Turku University of Applied Sciences. Turku, Finland, June 12-16, 2016. P. 606-618.

51. Bacigalupo M., Kampylis P., Punie Y., Van den Brande G. EntreComp: The Entrepreneurship Competence Framework. Luxembourg: Publication Office of the European Union, 2016. DOI: 10.2791/160811.

52. Bergmann J., Sams A. Flip Your Classroom: Reach Every Student in Every Class Every Day. Wash- 
ington DC: International Society for Technology in Education, 2012. P. 120-190.

53. Bergmann J., Sams A. Flipped Learning: Gateway to Student Engagement. International Society for Technology in Education, 2014. $182 \mathrm{p}$.

54. Dong X. Application of Flipped Classroom in College English Teaching // Creative Education. 2016. Vol. 7, № 9. P. 1335-1339.

55. Салманова Д.А., Ахмедбекова Р.Р. Подготовка магистрантов педагогического образования к проведению мониторинга // Вестник Челябинского государственного педагогического университета. 2016. № 1. C. $21-25$.

56. Понятие оценивания в образовании / Т.В. Загоруйко, С.Ю. Диденко, Е.И. Черепанская, Е.Е. Лактионова, Л.И. Титова, В.В. Лебедева // Молодой ученый. 2018. № 45. С. 240-242.

57. Белаш О.Ю., Чиркова А.А. Показатели внутреннего мониторинга качества образования: различия в оценке студентами и преподавателями важно- сти показателей // Инженерное образование. 2018. № 24. С. 166-173.

58. Чучалин А.И., Епихин А.В., Муратова Е.А. Планирование оценки результатов обучения при проектировании образовательных программ // Высшее образование в России. 2013. № 1. С. 13-20.

59. Шкунова А.А. Измерение и оценивание качества подготовки студентов по организационному поведению в системе дистанционного обучения // Coвременные научные исследования и инновации. 2015. № 6, ч. 5. С. 25-29.

60. Литвинова Т.Н., Юдина Т.Г., Русинова Т.В., Литвинова М.Г. Анкетирование студентов первого курса «Изучение химии глазами студентов» // Международный журнал прикладных и фундаментальных исследований. 2017. № 4-1. С. 178-181.

61. Михелькевич В.Н., Кравцов П.Г. Комплексная оценка готовности выпускников магистратуры к профессиональной деятельности // Самарский научный вестник. 2016. № 2 (15). С. 171-176.

\section{A MODERN VIEW ON SERVICE AND OPERATIONAL COMPETENCE DEVELOPMENT OF SPECIALISTS DEALING WITH HAZARDOUS PRODUCTION FACILITIES SAFE OPERATION} (C) 2019

Panychev Andrey Lvovich, head of Togliatti Interterritorial Department for Supervision of Industrial and Energy Security

Middle Volga Region Department of the Federal Service for Environmental, Technological and Nuclear Supervision (Togliatti, Samara Region, Russian Federation)

Gorina Larisa Nicolaevna, doctor of pedagogical sciences, professor of Industrial and Environmental Safety Management Department Togliatti State University (Togliatti, Samara Region, Russian Federation)

Abstract. The paper presents the results of the study aimed at improving the quality of specialists training in higher educational institutions who will fork for industrial enterprises where hazardous production facilities are operated. The quality of training depends on the level of industrial safety of hazardous production facilities and as a consequence the likelihood of accidents. At the moment, despite the general trend of reducing accidents at hazardous production facilities over the past ten years, their number remains quite significant. At the same time, social and economic damage from accidents can be estimated at 600-700 billion rubles per year, which will have a negative impact on the economic stability of the Russian Federation. The obligations of industrial enterprises where hazardous production facilities are operated and its employees are defined by the legislation. The content of education should take into account these basic requirements, which should be formed into separate themes. Accordingly, the modular principle is used in the design of the training content. The development of content in the form of modules will ensure the organizational and substantive unity of students training. We accept lectures and practical classes, as well as group and individual ones as the main methods of the educational process. Learning the material based on the results of lectures, practical training and self-training should allow students to form the qualities specified in our profesionogram. How the educational material proposed for study is learned should be checked during the control activities, starting from the initial-input control and ending with the final control.

Keywords: technology; professionogram; module; educational program; educational approach; training content; control; evaluation; monitoring; service and operational competence; specialist; industrial safety; hazardous production facility; accident.

УДК 37.378 .1

DOI 10.24411/2309-4370-2019-14309

Статья поступила в редакцию 23.09.2019

\section{УПРАВЛЕНИЕ КАЧЕСТВОМ ВЫСШЕГО ОБРАЗОВАНИЯ В УСЛОВИЯХ ЦИФРОВИЗАЦИИ} (C) 2019

Полупан Ксения Леонидовна, кандидат педагогических наук,

доцент института образования, руководитель службы обеспечения образовательного процесса Балтийский федеральный университет имени Иммануила Канта (2. Калининград, Российская Федерация)

Аннотация. В данной статье рассматриваются основные научные результаты исследования, связанные с введением в педагогическую науку нового понимания управления качеством высшего образования, связанного с цифровизацией образовательного процесса в университете. Суть состоит в том, что при взаимодействии обучающегося с другими субъектами образовательного процесса предоставляются условия, в которых 